\title{
Abstract to publication conversion in pediatric critical care medicine in Pakistan
}

\author{
Anwarul Haque ${ }^{1}$, Mohammad Shahzad ${ }^{2}$, Humaira Jurair ${ }^{2}$, Naveed Ur Rehman Siddiqui ${ }^{3}$, Sidra Ishaque $^{3}$, \\ Qalab Abbas ${ }^{3}$
}

${ }^{1}$ Department of Pediatrics, Liaquat National Hospital, Karachi; ${ }^{2}$ Department of Pediatrics, The Indus Hospital Karachi, Karachi, ${ }^{3}$ Department of Pediatrics and Child Health, Aga Khan University, Karachi, Pakistan

Background: To determine the rate of conversion of abstracts presented at conferences into full-text articles published in peer-reviewed journals in the field of pediatric critical care medicine (PCCM) in a developing country.

Methods: We retrospectively reviewed PCCM abstracts from Pakistan presented at national and international pediatric and critical care conferences over 10 years (January 2010 to March 2020). Data included abstract characteristics, such as presentation (poster/oral), presenter (fellow/resident), time of meeting (month and year), type of meeting, study design and topic; and publication characteristics, such as journal name, time (month and year) and first author. The primary outcome was publication rate of PCCM abstracts presented in meetings and time (months) from presentation to publication.

Results: A total of 79 PCCM abstracts were presented in 20 meetings during the study period. There were 65 poster presentations (82.28\%), of which 63 (79.74\%) were presented at international critical care conferences and all presenters were PCCM fellows. In total, 64 (81\%) abstracts were descriptive observational studies (retrospective: 50, 63.29\%) and prospective $(14,17.72 \%)$. Only one was an interventional randomized controlled trial. The publication rate of PCCM abstracts was 63.3\% (50/79) and the mean time to publication was $12.39 \pm 13.61$ months. The publication rate was significantly correlated to the year of publication $(P<0.001)$.

Conclusions: The PCCM abstract publication rate and mean time from presentation to publication was $63.3 \%$ and $12.39 \pm 13.61$ months, respectively, in a developing country.

Key Words: abstracts; critical care; meeting abstracts; pediatrics; publication; research

\section{INTRODUCTION}

Research is fundamental to advancing knowledge in every field of medicine, as well as exploring new therapies and solving contextual problems. Abstract presentation at national or international scientific meetings provides a gateway to sharing research findings and experiences with peers. It also serves as an opportunity to receive feedback from peers, which can contribute to preparation of a stronger submission for publication. Publication in a peer-review journal is considered a measure of research success because it requires rigorous peer review [1]. A large body of literature is available on the abstract to publication conversion rate, especially from surgical subspecialties; this rate ranges from $23 \%$ to $68 \%$ [2-4]. A Cochrane

\section{Original Article}

Received: September 21, 2020

Revised: December 2, 2020

Accepted: December 30, 2020

Corresponding author

Qalab Abbas

Department of Pediatrics and Child Health, Aga Khan University, Stadium Rd, 74800 Karachi 3500, Pakistan

Tel: +9234864795

E-mail: Qalab.abbas@aku.edu

Copyright @ 2021 The Korean Society of Critical Care Medicine

This is an Open Access article distributed under the terms of Creative Attributions Non-Commercial License (https:/I creativecommons.org/li-censes/by-nc/4.0/ which permits unrestricted noncommercial use, distribution, and reproduction in any medium, provided the original work is properly cited. 
review recently reported that more than half of results from abstracts and almost a third of randomized controlled trials (RCTs) initially presented as abstracts are not published [5]. Pediatric critical care medicine (PCCM) is a relatively new, fast growing discipline of pediatrics in low-and-middle-incomecountries (LMIC) like Pakistan. It is mandatory for PCCM fellows to complete a basic or clinical research project related to PCCM during their training period to pursue a career as an academic pediatric intensivist [6]. Scant data are available on abstract to publication conversion in the discipline of PCCM, particularly from Pakistan [7]. The purpose of this quantitative, descriptive, bibliometric study was to assess the conversion rate of abstracts, which were authored by researchers from Pakistan and focused on PCCM, that were presented in scientific meetings into publications in peer-reviewed journals.

\section{MATERIALS AND METHODS}

We retrospectively reviewed all abstracts related to the field of PCCM presented in national/international meetings from January 2010 to March 2020. Data were extracted from Google Scholar, PubMed, Pakmedinet (a local repository), our database publications from fellows in the three major academic centers in Karachi and by contacting all major authors (including previous fellows) identified through this research. The search strategy had both free text and MeSH terms including: "pediatric critical care medicine Pakistan" OR "Pediatric Intensive Care Unit Pakistan" OR "critically ill children Pakistan" OR "critically injured children Pakistan" OR "children Pakistan". Local journals and the institutional repository of one of the university hospitals (currently the only accredited training institute; Aga Khan University Hospital) were also searched using the same terms. The following data related to abstracts were collected on a structured sheet, including title, presentation (oral/poster), scope (clinical/basic/survey/education), study design (descriptive as prospective/retrospective, intervention, RCT, case report), topic (sepsis, cardiovascular system diseases, central nervous system diseases, respiratory system diseases, etc.), month and meeting (national/international). The characteristics of published articles include title, first author, name of journal, type of article (original article/brief report/ letter to editor, review article), published in national/regional/ international). Publication status was defined as an abstract published as a full-text article in peer-reviewed journals. A match was defined as adequate similarity between the abstract and publication with regards to title, author, methods and results. Gap was the time between abstract presentation at a

\section{KEYMESSAGES}

- Abstract to manuscript conversion is an important indicator of trainees' research in any specialty.

- Two thirds of abstracts in pediatric critical care medicine presented in scientific meetings by researchers from Pakistan were later published as full-text manuscripts after a mean duration of 1 year.

- More effort is needed to improve research in pediatric critical care in developing nations.

conference to publication in months. Outcome was the percentage of abstracts presented at either national or international conferences converted into a full manuscript as a publication [7]. Abstracts presented more than once were only counted once based on the first presentation.

Results are presented as mean with standard deviation for numerical variables and frequency and percentages for categorical variables. Descriptive and bivariate statistical analysis was computed using IBM SPSS ver. 22 (IBM Corp., Armonk, NY, USA). The Kaplan-Meier method was used to estimate publication rate over time. Institutional review board approval was not sought for this study because no personal or patient data were involved.

\section{RESULTS}

We found and analyzed 79 abstracts in the field of PCCM that were accepted for presentation at 20 pediatrics/critical care conferences from January 2010 to June 2020. Figure 1A presents the flow diagram of the search. The abstract characteristics are presented in Table 1. Poster and oral presentations accounted for 65 (82.28\%) and $14(17.72 \%)$, respectively. The largest number of abstracts $(17,21.5 \%)$ was presented in 2018. The publication rate was significantly correlated with the year of publication $(\mathrm{P}<0.001)$ (Figure $1 \mathrm{~B})$. The majority of abstracts $(63,79.4 \%)$ were presented at different international critical care meetings; of these 32 (40\%) were presented at three World Federation Pediatric Intensive and Critical Care Society conferences. The study design of these abstracts included clinical retrospective cross-sectional studies $(50,63.29 \%)$, prospective observational studies $(14,17.72 \%)$, and education $(6,7.59 \%)$ (Table 1). Topics of abstracts included sepsis $(13,16.45 \%)$, the central nervous system $(11,13.92 \%)$, the renal system $(10,12.65 \%)$ and the respiratory system $(8,10.12 \%)$. There was only one randomized controlled interventional trial and three multicenter studies in this bibliometric cohort. 

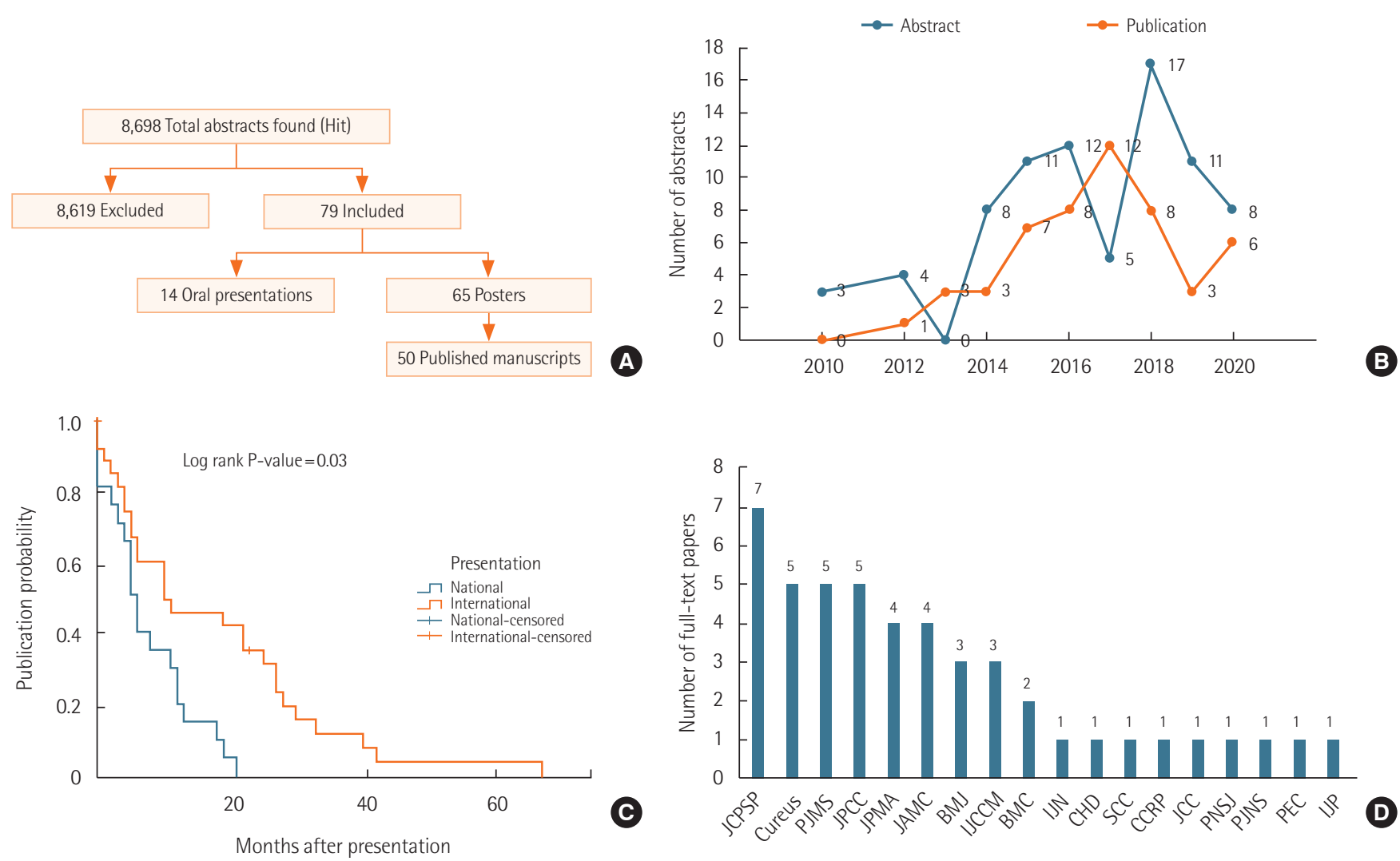

(D)

Figure 1. (A) Flow diagram of the abstract search. (B) Number of abstracts presented and published over the study period. (C) Publication probability comparison between national and international conferences. (D) Number of full-text papers published in different journals. JCPSP: Journal of College of Physicians and Surgeons Pakistan; PJMS: Pakistan Journal of Medical Sciences; JPCC: Journal of Pediatric Critical Care; JPMA: Journal of Pakistan Medical Association; JAMC: Journal of Ayub Medical College; BMJ: British Medical Journal; IJCCM: Indian Journal of Critical Care Medicine; IJN: Indian Journal of Neurotrauma; CHD: Congenital Heart Disease, CCRP: Critical Care Research and Practice; JCC: Journal of Critical Care; PJNS: Journal of Pediatric Neurosciences; PEC: Pediatric Emergency Care; IJP: Indian Journal of Pediatrics.

The conversion rate of abstracts to full-text articles published peer-review journals was $63.3 \%$ (50/79). Kaplan-Meier analysis showed a higher probability of publication for abstracts presented at national meetings compared to international meetings ( $\log$ rank $\mathrm{P}<0.03$ ) (Figure $1 \mathrm{C})$. The median time from presentation to publication was 6 months (range, 3-21 months) and the mean was $12.69 \pm 13.61$ months. Abstracts were published into 18 different journals, as shown in Figure 1D.

\section{DISCUSSION}

To the best of our knowledge, this is the second bibliometric report in the field of PCCM and the first from Pakistan. It also may be the first report on PCCM abstracts from an LMIC. PCCM in Pakistan started in 2007 when a board-certified PCCM physician returned to the country and started building a program. A fellowship in PCCM program in Pakistan was started in 2010 and more than dozen physicians have been trained through this program. Recently the program was accredited by College of Physicians and Surgeons Pakistan and three more training centers have been approved. A survey done in 2009 revealed that there were only 16 units in the whole country with a total 155 beds ( 1 bed/500,000 children) with only three units having a trained PCCM physician [8]. This situation has improved in the past 10 years. Examining research output provides an opportunity to identify gaps in knowledge and avenues for future research.

Our results showed an abstract conversion to full manuscript publication rate $(63.3 \%)$ that was a little better than previously reported (41\%) for PCCM abstracts. We included abstracts presented in 2019 and early 2020 so there is some possibility that these abstracts will also be converted into full-text manuscripts, based on the mean time to conversion described herein. Pediatric intensive care unit (PICU) in Pakistan remains a relatively young discipline with a long way to go. Though the number of abstracts have been not very encouraging but their 
Table 1. Characteristics of pediatric critical care medicine abstracts presented at different conferences by researchers from Pakistan

\begin{tabular}{|c|c|}
\hline Variable & Value $(n=79)$ \\
\hline \multicolumn{2}{|l|}{ Form of presentation } \\
\hline Oral & $14(17.72)$ \\
\hline Poster & 65 (82.28) \\
\hline \multicolumn{2}{|l|}{ Conference } \\
\hline National & $33(41.77)$ \\
\hline International & 63 (79.74) \\
\hline \multicolumn{2}{|l|}{ Study design } \\
\hline Retrospective & $50(63.29)$ \\
\hline Prospective & $14(17.72)$ \\
\hline Education & $6(7.59)$ \\
\hline Case report & $3(3.79)$ \\
\hline Audit & $2(2.53)$ \\
\hline Quality improvement project & $2(2.53)$ \\
\hline Randomized controlled trial & $1(1.26)$ \\
\hline Survey & $1(1.23)$ \\
\hline \multicolumn{2}{|l|}{ Topic } \\
\hline Cardiovascular system & $6(7.59)$ \\
\hline Neurological system & $11(13.92)$ \\
\hline Respiratory system & $8(10.12)$ \\
\hline Renal system & $10(12.65)$ \\
\hline Sepsis/infectious diseases & $13(16.45)$ \\
\hline Oncological & $5(6.32)$ \\
\hline Miscellaneous & $26(32.91)$ \\
\hline Award & $2(2.53)$ \\
\hline Grant & $2(2.53)$ \\
\hline $\operatorname{Gap}^{a}(\mathrm{mo})$ & $6(3-21)$ \\
\hline Published & $50(63.29)$ \\
\hline
\end{tabular}

Values are presented as number (\%) or median (range).

Time between abstract presentation at a conference to publication in months.

impact in terms of presentation specially in international conferences and conversion into publication has been very good. Another exciting finding is that all of these abstracts were presented by PCCM fellows. This suggests that PICU in Pakistan has a bright future.

A recent Cochrane review reported an approximately $44 \%$ conversion rate of abstracts presented at the conference into full-text manuscripts [5]. Most of these kinds of assessments were done in various disciplines of surgical meetings, especially orthopedics $[2,9,10]$. There were only few pediatrics reports available that employed bibliometric analysis $[11,12]$. Research is a vital component for any specialty of modern medicine in order to explore new frontiers in diseases and their management. There is growing pressure among clinicians in academic settings for promotions in their future career [13]. Research is also an important aspect of solving contextual problems. With time it has become evident that a therapy or a protocol that works well in one geographic region may not work in another region. Previous studies have reviewed publication rates after pediatric meetings and found them to vary from $13 \%$ to $62 \%$ within 60 months after the conference [12,14-17]. We found that $63.3 \%$ of abstracts presented in meetings were published as full-text papers within a mean time to publication of $12.31 \pm 13.61$ months.

Basu and Pollack [7] showed that 41\% of PCCM abstracts presented at national pediatric and critical care conferences were published as a full-text articles in peer-reviewed journals with a mean time to publication of $22 \pm 3$ months. One such neonatal report demonstrated that only $13.7 \%$ of abstracts from a neonatal conference were converted into a publication in the next four years $[11,16]$. Herrmann et al. [11] reported a $33.6 \%$ publication conversion rate of abstracts presented at academic meetings in the field of pediatric hospital medicine. In a bibliometric report of annual pediatric hematology-oncology meetings, a total of $62 \%$ abstracts were published in peer-reviewed journals within a median time to publication of 19 months [17]. Few pediatric surgeries described the fate of abstracts and conversion to full publication $[14,15,18]$.

Most of the data $(81 \%)$ in our study were both retrospective and prospective clinical observational clinical projects like Basu and Pollack [7]. Similar trends in clinical projects in PCCM were seen in national and international journals from India in the last two decades [13]. Nearly $100 \%$ of clinical PCCM fellows presented at international critical care conferences, as compared to $36.5 \%$ in Basu and Pollack [7]. An important observation in this project was the paucity of randomized controlled trails $(n=1)$. RCTs are the gold standard for research and provide the highest level of evidence for the efficacy of therapeutic interventions [19]. However, other bibliometric reports in various disciplines had similar observations, especially surgical allied $[1,2]$.

There are several limitations to this study. First, only a small number of PCCM abstracts $(n=79)$ were presented over the 10 -year period, reflecting the newness of the field and the scarcity of practicing physicians in our country. PCCM is a relatively new discipline but is growing very fast in LMICs. The strength of this study is that it is only the second analysis of PCCM abstract conversion into full publication. The PCCM abstract publication rate and mean time to publication from presenta- 
tion were $63.3 \%$ and $12.39 \pm 13.61$ months, respectively, in our developing country. Our results are in parallel with other bibliometric studies. Future efforts should focus on improving the number of randomized controlled and multi-center studies published.

\section{CONFLICT OF INTEREST}

No potential conflict of interest relevant to this article was reported.

\section{ORCID}

Qalab Abbas

https://orcid.org/0000-0003-4378-5197

\section{AUTHOR CONTRIBUTIONS}

Conceptualization: QA, AH. Data curation: MS, QA. Formal analysis: QA, AH. Project administration: AH. Methodology: QA, NRS, HJ. Writing-original draft: AH, QA, HJ, NRS, SI. Writing-review \& editing: all authors.

\section{REFERENCES}

1. E JY, Ramulu PY, Fapohunda K, Li T, Scherer RW. Frequency of abstracts presented at eye and vision conferences being developed into full-length publications: a systematic review and meta-analysis. JAMA Ophthalmol 2020;138:689-97.

2. Trost M, Langer F, Lechler P, Schröder F, Wetterkamp M, Schulte TL, et al. Publication rate of abstracts presented at the Congress of the European Federation of National Associations of Orthopaedics and Traumatology (EFORT). Orthop Traumatol Surg Res 2019;105:1453-7.

3. Winnik S, Raptis DA, Walker JH, Hasun M, Speer T, Clavien PA, et al. From abstract to impact in cardiovascular research: factors predicting publication and citation. Eur Heart J 2012; 33:3034-45.

4. Bovonratwet P, Webb ML, Ondeck NT, Shultz BN, McLynn RP, Cui JJ, et al. High publication rate of abstracts presented at lumbar spine research society meetings. Int J Spine Surg 2018;12: 713-7.

5. Scherer RW, Meerpohl JJ, Pfeifer N, Schmucker C, Schwarzer G, von Elm E. Full publication of results initially presented in abstracts. Cochrane Database Syst Rev 2018;11:MR000005.

6. Morrison WE, Helfaer MA, Nadkarni VM. National survey of pediatric critical care medicine fellowship clinical and re- search time allocation. Pediatr Crit Care Med 2009;10:397-9.

7. Basu S, Pollack MM. Outcome of pediatric critical care medicine abstracts presented at north American academic national meetings. Pediatr Crit Care Med 2017;18:795-9.

8. Ladak LA, Hamid MH, Mirza S, Siddiqui NR, Bhutta ZA. A national survey of pediatric intensive care units in Pakistan. J Crit Care Med 2014;842050.

9. Smart RJ, Susarla SM, Kaban LB, Dodson TB. Factors associated with converting scientific abstracts to published manuscripts. J Craniofac Surg 2013;24:66-70.

10. Amirhamzeh D, Moor MA, Baldwin K, Hosalkar HS. Publication rates of abstracts presented at pediatric orthopaedic society of North America meetings between 2002 and 2006. J Pediatr Orthop 2012;32:e6-10.

11. Herrmann LE, Hall M, Kyler K, Cochran J, Andrews AL, Williams DJ, et al. The pipeline from abstract presentation to publication in pediatric hospital medicine. J Hosp Med 2018;13: 90-5.

12. Carroll AE, Sox CM, Tarini BA, Ringold S, Christakis DA. Does presentation format at the Pediatric Academic Societies' annual meeting predict subsequent publication? Pediatrics 2003; 112:1238-41.

13. Bhalala U, Bansal A, Chugh K. Advances in pediatric critical care research in India. Front Pediatr 2018;6:150.

14. Nasir AA, Ameh EA. Fate of abstracts presented at Association of Paediatric Surgeons of Nigeria annual meetings. Afr J Paediatr Surg 2012;9:132-6.

15. Nasir AA, Ameh EA, Poenaru D. Completion publication of abstracts presented at the scientific meetings of the Pan-African Pediatric Surgical Association. Afr J Paediatr Surg 2013;10: 246-51.

16. Singh A, Solanki P, Mishra D. Publication rate of scientific papers presented at the XXVI Annual Convention of National Neonatology Forum (NEOCON 2006). Indian J Pediatr 2015; 82:25-8.

17. Salami K, Alkayed K. Publication bias in pediatric hematology and oncology: analysis of abstracts presented at the annual meeting of the American Society of Pediatric Hematology and Oncology. Pediatr Hematol Oncol 2013;30:165-9.

18. Greig CJ, Zhang L, Armenia SJ, Park CJ, Fischer AC, Caty MG, et al. The impact of pediatric surgical specialty meetings: a 5-year analysis of presented abstracts. J Surg Res 2019;238:1622.

19. Akobeng AK. Understanding randomised controlled trials. Arch Dis Child 2005;90:840-4. 